\title{
Preliminary Entomological and Parasitological Studies in Humboldt, Aripuanā, Mato Grosso State, Brazil.
}

\author{
R. Lainson $(*)$ \\ R. D. Ward (*) \\ D. G. Young $[* *)$ \\ J. J. Shaw (*) \\ H. Fraiha (*)
}

\begin{abstract}
The preliminary results are given of studies on the sandfly fauna (Diptera: Psychodidae) in forest surrounding the Humboldt Research Centre, Município of Aripuanã, Mato Grosso State, Brazil. A total of 712 sandflies were obtained, including 26 different species: of these, 387 were caught off human bait; 317 from tree-trunks; 4 in a malaise-trap; 3 in rodent baited oil traps; and 1 in a light-trap. Man-biting species were absent or very rare during studies in the dry season (August and September, 1974), but relatively abundant at the end of the rainy season (June, 1975): this suggests a seasonal transmission of leishmaniasis. The species at present known as Lutzomyia anduzei of Floch \& Abonnenc (1942) was a major man-biter. this species is an important vector of cutaneous leishmaniasis in North Pará, Brazil, and could be responsible for transmission in Aripuanâ. Among a total of 349 female sandflies dissected, promastigote flagellates were found in 2 Lutzomyia yuilli; epimastigote flagellates in 1 L. yuilli; a microsporidian in Psychodopygus (1) complexus; a gregarine, probably Monocystis chagasi, in $\mathbf{P}$. davisi; and a nematode larva in $\mathbf{P}$. complexus. Inoculation of the promastigote flagellates into the skin of hamsters failed to give Leishmania infections: possibly they were developmental stages of some other parasite. Two research workers of Project RADAM acquired cutaneous leishmaniasis in the Humboldt area; and 6 cases of malaria were diagnosed, 3 due to $P$. falciparum and 3 to $P$. vivax. Transmission of malaria was shown to be taking place in the camp site itself. Finally, man-biting "black-flies" (Diptera: Simuliidae) were found to be a serious problem, necessitating constant use of insect repellent.
\end{abstract}

\section{INTRODUCTTON}

In January, 1973, plans were laid by the Minister of the Interior, the Minister of Edu- cation, and the Governor of the State of Mato Grosso, to establish a pioneer nucleus of workers to investigate and develop the region of Aripuanã, Mato Grosso.

Health hazards for such personel were clearly important factors to consider, and workers of the Instituto Evandro Chagas were among those asked to initiate a programme of epidemiological research, principally on the zoonotic diseases likely to be encountered in the region. The Department of Parasitology of this Institute has for long been interested in the problem of cutaneous leishmaniasis in Brazil, in particular the identification of the major phlebotomine vectors of the disease and reservoir hosts among the wild animals (Lainson \& Shaw, 1973). The establishment of good working facilities in a relatively natural, forested area such as the Humboldt Centre in Aripuanã was thus welcomed as a useful opportunity to extend these studies. We present, here, some preliminary findings on trie sandfly (Phlebofominae) fauna of the forest surrounding the Centre.

The Municipio of Aripuanã is situated on the river Aripuanã and is limited by the State boundaries of Amazonas, Pará, Federal Territory of Rondônia, and the Municipios of Diamantino, Porto dos Gauchos in the State of Mato Grosso, and the locality known as Chapada dos Guimarães also in the State of Mato Grosso. The precise geographical situation is latitude $7^{\circ}, 19^{\prime}, 45^{\prime \prime} \mathrm{N}$ and $12^{\circ}, 22^{\prime}, 30^{\prime \prime} \mathrm{S}$ : longitude $55^{\circ}, 54^{\prime}, 15^{\prime \prime} \mathrm{E}$ and $16^{\circ}, 31^{\prime}, 15^{\prime \prime} ' \mathrm{~W}$ (Fig. 1) .

['] - Instituto Evandro Chagas da Fundação Serviços de Saúde Pública, Belém, Pará, Brasil.

(") - Department of Entomology \& Nematology, University of Florida, Gainesville, Florida 32611, U.S.A.

(1) - Some authorities (including D. G. Young) prefer to use the name Psychodopygus as a sub-genus of Lutzomyia, e.g. Lutzomyia (Psychodopygus) complexus. 


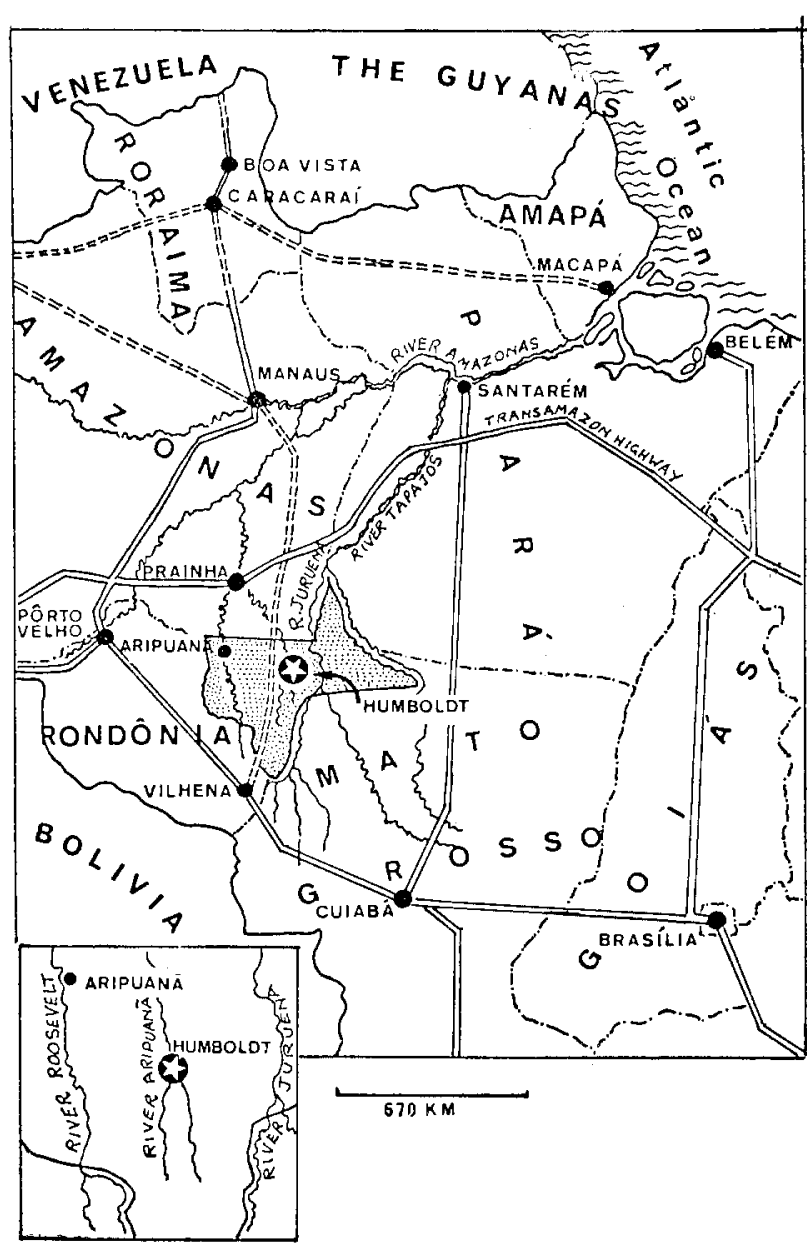

Fig. 1. - Location of the Humboldt Research Centre, Aripuanã Project.

The rainy season, ever important in its influence on the phlebotomine population, is approximately from October to April, with the heaviest rainfall from January to March: with an average of about $2,000 \mathrm{~mm}$ per year. The altitude is 300 metres above sea level, and the climate is equatorial and very humid.

In total area the Municipio of Aripuerrã covers $140,000 \mathrm{k}^{2}$, and its principal geographic features include the rivers Roosevelt, Aripuanã, Juruena and Teles Pires, and the Dardanelos waterfall, of the Aripuanã river, which is 130 $\mathrm{m}$ high. The region is densely forested for 95 per cent of its area and the population census for 1970 listed only 2,248 inhabitants, with the largest settlement comprising only 85 persons. In the south, the Municipio of Aripuanã includes a large part of the Cinta-Larga indian reserve.
Close to the Humboldt Centre, there already existed a small collection of thatched houses occupied by employees of a local rubber collector: sanitary conditions were very poor. The Humboldt Centre itself em-, ployed a small maintenance staff, who also tended the needs of visiting scientists. Apart from malaria, which was known to be common among the local inhabitants, there was no available information regarding leishmaniasis or other health problems.

\section{Materials AND METHODS}

Anthropophilic sandflies were collected off human bait, at night, usually between the hours of 19.00 and 21.00. Capture sites were selected from a variety of terrains, including high, dry forest ("terra firme") and more low-lying, swampy areas ("igapó"). Rodent-baited, oiled traps were also set in the same localities, in attempts to indicate sandfly species attracted to rodents or other small forest mammals. They were variously baited with laboratory hamsters or the wild rodent Proechimys guyannensis. Other sandflies were captured, with aspirators, from their resting-sites on the trunks of the larger trees, with a "malaisetrap", or in light-traps.

Móst of the anthropophilic sandflies were dissected, either immediately on return to the improvised laboratory or the following morning after preservation in the refrigerator, at $4^{\circ} \mathrm{C}$. Dissection was in sterile 0.85 per cent saline: the gut of each fly was examined microscopically for the presence of flagellates or other parasites, using phase-contrast illumination, and identification of the female sandfly species was based largely on spermathecal characters.

Any promastigote flagellates encountered were immediately taken up in a $1.0 \mathrm{ml}$ syringe, with a little saline, and inoculated intradermally into the nose or foot of a hamster. Male and female specimens of sandflies taken from tree trunks, malaise-trap and light-trap were used only for taxonomic purposes.

Three separate visits were made to the study area: from 12-19 August, 1974; 11-15 September, 1974; and 13-21 June, 1975. 


\begin{tabular}{|c|c|c|c|c|c|c|c|c|c|c|}
\hline \multirow{4}{*}{ Species } & \multicolumn{9}{|c|}{ Date and Method of Capture } & \multirow{4}{*}{ 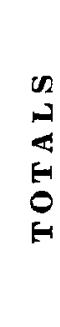 } \\
\hline & \multicolumn{6}{|c|}{$\begin{array}{c}\text { August } \\
1974\end{array}$} & \begin{tabular}{|} 
Septem- \\
ber 1974
\end{tabular} & \multicolumn{2}{|c|}{$\begin{array}{c}\text { June } \\
1975\end{array}$} & \\
\hline & \multicolumn{2}{|c|}{$\begin{array}{l}\text { Tree- } \\
\text { trunks }\end{array}$} & \multicolumn{2}{|c|}{$\begin{array}{l}\text { Malaise- } \\
\text { trap }\end{array}$} & \multicolumn{2}{|c|}{$\begin{array}{l}\text { Light. } \\
\text { trap }\end{array}$} & $\underset{\text { bait }}{\text { Human }}$ & $\begin{array}{c}\text { Human } \\
\text { bait }\end{array}$ & $\begin{array}{c}\text { Rodent } \\
\text { bait }\end{array}$ & \\
\hline & $\hat{o}$ & q & $\hat{o}$ & q & $\hat{\sigma}$ & q & $q$ & 우 & 우 & \\
\hline $\begin{array}{l}\text { Brumptomyia cunhai } \\
\text { Brumptomyia sp. } \\
\text { Lutzomyia evangelistai } \\
\text { L. anduzei F \& A } \\
\text { L. antunesi } \\
\text { L. whitmani } \\
\text { L. yuilli } \\
\text { L. (Nyssomyia) sp. } \\
\quad 260.44 \\
\text { L. (Nyssomyia) sp. } \\
\text { L. micropyga } \\
\text { L. dendrophila } \\
\text { L. shannoni } \\
\text { L. scaffi } \\
\text { L. lutziana } \\
\text { L. lichyi } \\
\text { L. sp. (longispina Gp) } \\
\text { L. monstruosa } \\
\text { L. furcata } \\
\text { L. tuberculata } \\
\text { L. acanthopharynx } \\
\text { Psychodopygus } \\
\text { complexus } \\
\text { P. bispinosus } \\
\text { P. carrerai } \\
\text { P. davisi } \\
\text { P. hirsutus } \\
\text { P. lainsoni } \\
\text { Unidentified spp. }\end{array}$ & $\begin{array}{r}1 \\
1 \\
1 \\
1 \\
1 \\
\\
\\
\\
\\
1 \\
72 \\
148 \\
5 \\
3 \\
\\
\\
\\
2 \\
5 \\
17\end{array}$ & $\begin{array}{l}3 \\
4 \\
\\
1 \\
1\end{array}$ & 1 & $\begin{array}{l}1 \\
1\end{array}$ & & 1 & 7 & $\begin{array}{r}129 \\
4 \\
2 \\
39 \\
3 \\
3 \\
11\end{array}$ & 1 & $\begin{array}{r}4 \\
4 \\
2 \\
90 \\
2 \\
1 \\
78 \\
\\
2 \\
1 \\
1 \\
129 \\
148 \\
6 \\
4 \\
1 \\
1 \\
1 \\
4 \\
10 \\
20 \\
\\
131 \\
4 \\
2 \\
48 \\
3 \\
3 \\
12\end{array}$ \\
\hline TOTALS & 258 & 59 & 1 & 3 & 0 & 1 & 7 & 380 & 3 & 712 \\
\hline
\end{tabular}

$\left({ }^{*}\right)$ - Females of $\mathbf{L}$. dendrophilo and $\mathbf{L}$. shannoni indestinguishable.

\section{RESULTS}

The 26 species of sandflies captured, by all methods, are listed in Table 1.

The first visit, in August, 1974, was well within the dry season and attempts to obtain sandflies from human bait were unsuccessful. Smali numbers were found on tree-trunks, however, and a rigorous search gave a total catch of 317 . Only 4 specimens were caught in the malaise-trap, and 1 in a light-trap: no animal-baited traps were set on this occasion. Altogether, 19 different species were recorded: all material was used for taxonomic purposes only.

In September, 1974, there had been sporadic showers of rain: neverthless, only 7 sandflies were taken from human bait during a total of 20 man-hours of catching, and all were $P$. davisi. No other method of capture 
was attempted and all material was used for taxonomy.

The third visit to Aripuanã was more fruitful, doubtless because it coincided with the end of the rainy season and the forest was noticably more moist. A total of 387 sandflies were caught from human bait in approximately 20 man-hours, and they included 11 different species. Rodent-baited traps gave poor results in all localities, providing only 2 female $P$. complexus and 1 female $P$. davisi: no other methods of capture were employed. We dissected 349 of the sandflies taken with human bait, and the 3 that were caught off the rodent-baited trap.

Promastigote infections were found in ? specimens of L. yuilli Young \& Porter 1972. Most of the flagellates in the first fly were attached, singly or in clusters, to the wall of the pylorus ("hindgut triangle"), with smaller numbers extending throughout the ileum and down to the rectum: others were seen swimming rapidly in the lumen. The individual parasites varied greatly in form; from the classical, elongate "leptomonad" to stumpy, oval or almost rounded bodies. The length $\mathrm{ci}$ the single flagellum was also very variable; little more than the length of the body in the short or rounded forms attached to the gut wall, but often two or three times its length in the elongated, free parasites. Some of the latter were extremely thin, and moved with remarkable rapidity. Elongated forms were also abundant in the midgut, but none were seen in any part of the foregut. Infection in the second $L$. yuilli was similar, but restricted to the hindgut.

A third specimen of L. yuilli was infected with stumpy epimastigote flagellates, probably the developmental stages of a trypanosome. They showed sluggish movements and were apparently limited to the midgut.

Developmental stages and mature spores of a microsporidian were seen in the malpighian tubules of a single $P$. complexus, the parasite causing considerable deformation of the tubules.

A gregarine was noted in a specimen of $P$. davisi: both trophozoites and mature oocysts were present, the latter almost filling the accessory glands. Morphologically the parasite was similar to Monocystis chagasi, previously described in Lutzomyia longipalpis (Adler \& Mayrink, 1961) and Lu. flaviscutellata (Lewis, et al., 1970).

Finally, a nematode larva was encountered in the hindgut of a $P$. complexus, which showed abundant remains of a previous blood-meal filling the midgut.

Hamsters were inoculated, intradermally. with the promastigotes from the $2 L$. yuilli. On neither occasion, however, was, it possible to find Leishmania at the site of inoculation, one year later, either by direct examination or by NNN culture of skin-snips.

The limited time available did not permit an examination of forest mammals for Leishmania infection. There is no doubt regarding the presence of a reservoir of infection in the Humboldt area, however, for two casos of cutaneous leishmaniasis were diagnosed in men returning to Belém from work on the Aripuanã Project. Isolation of the parasite from their skin lesions, in hamsters and NNN culture medium, has shown it to be of the $L$. braziliensis complex, and further studies are in progress to obtain a more precise identification.

The problem of malaria in the neighbourhood of the Humboldt was amply confirmed by the examination of blood-films from 6 febrile persons. Three of them had $P$. falciparum infections, and three $P$. vivax: all showed mature gametocytes, and transmission was clearly in progress in the Humboldt Centre itself, for a $P$. vivax infection was acquired there by one of our I.E.C. staff.

Finally, several species of Simulium (Diptera: Simuliidae) were collected in pupal or adult stages. Two species were found biting man: one of these, a small fly of the $S$. amazonicum complex, was a severe problem in the Humboldt area, attacking from dawn to dusk in numbers which made field work extremely difficult without constant application of insect-repelent. 


\section{DISCUSSION}

The observations to date are insufficient to draw very firm conclusions, but our failure to obtain sandflies from human bait during a whole week in the dry season does suggest that transmission of cutaneous ieishmaniasis in this area may be limited to the rainy season and shortly afterwards. Furthermore, subsequent captures with human bait showed a patchy distribution of some of the anthropophilic species, which in turn suggests that endemic foci of the disease may share a similarly uneven pattern.

The apparent absence of the sandfly Lutzomyia flaviscutellata surprised us, particularly as we used traps baited with rodents, to which this insect is highly attracted. $L u$. flaviscutellata is the vector of Leishmania mexicana amazonensis in the Amazon region (Lainson \& Shaw, 1968; Shaw \& Lainson, 1968): we have found it to be common in almost all areas we have studied, including "gallery" forest in the Serra do Roncador area of Mato Grosso (Lainson \& Shaw, 1970) which shares a similarly clearly demarked wet and dry season as that seen in Aripuanã.

Perhaps the most significant observation during these studies has been the abundance of that species at present known as Lutzomyia anduzei of Floch \& Abonnenc (1942). This sandfly has recently been shown to be an important vector of $L$. braziliensis guyanensis, the causitive agent of cutaneous leishmaniasis ("pian-bois") in the extreme north of Pará State (Lainson, et al., 1976). Whether or not it is also a vector in the Aripuanã region remains to be seen.

The failure of promastigotes in $L$. yuilli to produce detectable Leishmania infections in the inoculated hamsters suggests one or two things. Either they were monogenetic flagellates of this insect, or they were developmental stages of another parasite taken up in a blood-meal from some wild mammal. In the former case one might expect the incidence of infection in $L$. yuilli to have been much higher and, in addition, we have yet to secure any definite evidence of any monogenetic flagellate infection in the several thousand wild- caught sandflies we have dissected in Brazil. We feel, therefore, that the second hypothesis is most likely the correct one: in this respect Endotrypanum, the intra-erythrocytic trypanosomatid of the sloth Choloepus didactylus, remains a likely suspect. Shaw (1969) found this parasite to develop as a promastigote infection in the hindgut station of experimentally infected sandflies, in Panama, and subsequently (unpublished observations) isolated Endotrypanum from a naturally infected sandfly in that country.

The nature of the epimastigotes in the midgut of the third $L$. yuilli is equally problematical. We have found trypanosome infections in a number of wild animals, any of which might have been the source of this insect's infection. It is worth noting, however, that apart form Endotrypanum, the sloth $C$. didactylus also harbours Trypanosoma spp., (Shaw, 1969): it is tempting to suggest, therefore, that both promastigote and epimastigote infections of L. yuilli may have originated from this same animal.

Little more can be added to our record of a microsporidian in $P$. complexus and a Monocystis-like gregarine in $P$. davisi, for time did not permit a detailed study of this material. Both have been encountered in a variety of other sandfly species in the course of our studies elsewhere in Brazil (unpublished observations), and nematode larvae have also been seen on less frequent occasions.

Further study of sandflies in the Aripuanã region is needed to resolve the question of the promastigote infections in $L$. yuilli, and to pinpoint the vectors and wild mammal reservoirs of Leishmania in this poorly studied area.

\section{ACKNOWLEDGEMENTS}

These studies were carried out under the auspices of the Brazilian Research Council (C.N.Pq.) and the Wellcome Trust, London. Dr. D. G. Young's visit was financed by the Walter Reed Army Institute of Research, U.S.A. We are indebted to the Brazilian Air Force (F.A.B.) and the RADAM Project (Radar na Amazônia) for air transport; to Sr. Tibor 
Paal and his staff at the Humboldt Centre, for their hospitality during our visits; and to Dra. Zéa Lins for assistance in the capture of sandflies, with human bait, on numerous occasions.

\section{SUMÁrIo}

São apresentados os resultados preliminares do estudo da fauna flebotomínea (Diptera, Psychodidae, Phlebotominae) da floresta que circunda o Centro de Pesquisa de Humboldt, Aripuanã, Estado de Mato Grosso, Brasil.

Foi obtido um total de 712 flebotomíneos, incluindo 26 espécies diferentes, 387 dos quais capturados com isca humana, $317 \mathrm{em}$ troncos de árvores, $4 \mathrm{em}$ armadilha tipo "malaise", 3 com isca-roedor, e 1 com armadilha luminosa.

Espécies antropófilas foram muito raras durante os estudos na época seca (agosto e setembro), mas relativamente abundantes durante as investigaçóes no fim da época chuvosa (junho), sugerindo a ocorrência de uma transmissão sazonal de leishmaniose cutânea na área.

Lutzomyia anduzei seg. Floch \& Abonnenc (1942), foi uma das espécies antropófilas mais comumente encontradas, e, sendo um dos vetores mais importantes da leishmaniose cutânea no Norte do Pará, Brasil, é possível que seja também responsável pela transmissão na área do Aripuanã.

349 fêmeas de flebotomineos foram dissecadas, tendo sido encontrados: flagelados do tipo promastigoto em 2 Lutzomyia yuilli, e do tipo epimastigoto em um exemplar da mesma espécie; um microsporídio, em 1 Psychodopygus complexus; uma gregarina, provavelmente Monocystis chagasi, em 1 P. davisi; e uma larva de nematódeo, em 1 P. complexus.

A inoculação dos flagelados promastigotos na pele de hamster não produziu infecção leishmaniótica, possivelmente por se tratar de estágio de desenvolvimento de qualquer outro parasita, como Endotrypanum, por exemplo.

Dois casos de leishmaniose cutânea foram registrados em pesquisadores do Projeto RADAM trabalhando na área de Humboldt, assim como 6 casos de malária, determinados por $P$. falciparum (3) e P. vivax (3). Finalmente, a grande densidade de piuns (Diptera: Simuuilidae) antropófilos, constritui um sério problema na área, obrigando ao uso constante de repelentes.

\section{LITERATURE CITED}

AdLer, S., \& MAYRINK, W.

1961 - A gregarine, Monocystis chagasi n. sp. of Phlebotomus longipalpis. Remarks on the acessory glands of P. longipalpis. Rev. Inst. Méd. Trop. São Paulo 3, 230-238.

FLoch, H., \& AbonneNC, E.

1942 - Phlébotomes de la Guyane Française. III. Sur P. intermedius Lutz \& Neiva, 1912. Publication de l'Institut Pasteur de la Guyane Français et du territoire de l'Inini. N. $30,1-16$.

LAINSON, R., \& SHAw, J.J.

1968 - Leishmaniasis in Brazil: I. Observations on enzootic rodent leishmaniasis-incrimination of Lutzomyia flaviscutellata (Mangabeira) as the vector in the lower Amazonian basin. Trans. R. Soc. trop. Med. \& Hyg. 62, 385-395.

1970 - Leishmaniasis in Brazil: V. Studies on the epidemiology of cutaneous leishmaniasis in Mato Grosso State, and observations on two distinct strains of Leishmania isolated from man and torest animals. Trans. R. Soc. trop. Med. \& Hyg. 64, 654-667.

1973 - Leishmanias and leishmaniasis of the New World, with particular reference to Brazil. Bull. Pan Amer. Hith. Org. 7, (4), 1-19

Lainson, R., Ward. R.D. \& Shaw, J.J.

1976 - Cutaneous leishmaniasis in north Brazil: Lutzomyia anduzei as a major vector. Trans. R. Soc. trop. Med. \& Hyg. 70, 171-172.

LEwis, D.J., Lainson, R., \& Shaw, J.J.

1970 - Determination of parous rates in Phlebotomine sandflies with special reference to Amazonian species. Bull. ent. Res. 60, 209-219.

SHAW, J.J.

1969 - "The haemoflagellates of sloths" London School of Hygiene \& Tropical Medicine Memoir 13, H. K. Lewis \& Co. Ltd. London.

SHaw, J.J., \& Lainson R.

1968 - Leishmaniasis in Brazil: II. Observations on enzootic rodent leishmaniasis in the lower Amazon Region - the feeding habits of the vector, Lutzomyia flaviscutellata, in reference to man, rodents and other animals. Trans. $R$. Soc. trop. Med. \& Hyg. 62, 396-405. 